\title{
A PRÁTICA DOCENTE DOS PROFESSORES DE ENGENHARIA DA PUC MINAS NA PERSPECTIVA DE ALUNOS E PROFESSORES ${ }^{1}$
}

Gláucia Nolasco de Almeida Mello-gnamello@pucminas.br

Pontifícia Universidade Católica de Minas Gerais - Departamento de Engenharia Civil

Rua Dom José Gaspar, 500, Coração Eucarístico

CEP 30535-901 - Belo Horizonte - MG

Mariana Veríssimo Soares de Aguiar e Silva - mverissimo@ pucminas.br

Instituição de Ensino, Faculdade ou Departamento - Departamento de Educação

Rua Dom José Gaspar, 500, Coração Eucarístico

CEP 30535-901 - Belo Horizonte - MG

Resumo: Este artigo é originário de uma pesquisa financiada pelo programa FIP PUC Minas cujo principal objetivo foi compreender a prática docente na sala de aula dos cursos de engenharia da PUC Minas para transformá-la, se necessário. O instrumento utilizado para a coleta de dados que serviu de base para as discussões neste texto foi o questionário impresso respondido pelos alunos em sala de aula e o questionário online respondido pelos professores. Todos os alunos dos cursos de Engenharia Civil, Engenharia de Energia e Engenharia Metalúrgica, matriculados no $8^{\circ}, 9^{\circ}$ e $10^{\circ}$ períodos e, todos os professores dos mesmos cursos, foram convidados a participar da pesquisa. Concordaram em participar nesta etapa da pesquisa um total de cem pessoas - setenta e dois alunos e vinte e oito professores. Tanto para os professores quanto para os alunos, os principais pontos positivos na prática pedagógica dos professores dos referentes cursos foram: metodologias e técnicas adotadas, conhecimento dos professores e relação professor-aluno. Os alunos também apontaram que os principais pontos a serem melhorados são as metodologias e as técnicas adotadas e, ainda a relação professoraluno. Os professores consideraram como aspectos a serem melhorados, as metodologias e as técnicas adotadas bem como as estratégias de avaliação. Esta investigação evidencia a importância das metodologias e técnicas adotadas para a prática pedagógica e, ao mesmo tempo destaca, a necessidade da transformação desta para que se possa contribuir efetivamente para o desenvolvimento das habilidades e competências dos futuros engenheiros.

Palavras-chave: Ensino de engenharia. Práticas pedagógicas. Desenvolvimento de competências.

\section{INTRODUÇÃO}

Modificar os currículos dos cursos de engenharia considerando uma nova abordagem com foco no desenvolvimento de habilidades e competências por parte do aluno exige o envolvimento por parte dos professores no sentido de reverem suas práticas pedagógicas. $\mathrm{O}$ profissional professor(a) é convidado a participar do processo de discussão e construção do Projeto Pedagógico se comprometendo, inclusive, com o aperfeiçoamento de sua formação como docente. Existem diversas iniciativas, nacionais e internacionais, no sentido de promover o aprimoramento das técnicas e metodologias adotadas no ensino superior de engenharia com a finalidade de ajudar o professor a implementar uma prática docente capaz de conduzir o 
estudante ao desenvolvimento de habilidades e competências. Por exemplo, Cruz (2019) reforça a importância da engenharia popular (EP) cujo destaque é o desenvolvimento da responsabilidade social, senso crítico, capacidade de solucionar problemas e criatividade. A EP envolve três perspectivas que se complementam: a economia solidária, a tecnologia social e a extensão universitária. Alguns fatores destacados pelo autor que propiciam a formação de engenheiros voltada para EP são: o envolvimento do aluno em projetos e trabalhos de extensão, oferta de disciplinas com enfoque em Ciência, Tecnologia e Sociedade e exigência de estágio curricular de vivência.

Para a implantação de atividades e disciplinas considerando os fatores destacados por Cruz (2019), é necessário que seja alterada a estrutura curricular dos cursos. Keller-Franco e Masetto (2018) chamam a atenção para a estrutura curricular baseada em projetos. Trata-se de uma forma de trabalhar considerada por eles muito adequada aos cursos de engenharia. Uma estrutura pedagógica baseada em projeto pressupõe uma forte relação entre teoria e prática além de exigir que os trabalhos sejam baseados na interdisciplinalidade. Neste contexto destacam-se o desenvolvimento e valorização de habilidades como a capacidade crítica, a capacidade de solucionar problemas, a criatividade, a colaboração e o domínio de fontes para a busca de informações, como característica de um pesquisador, entre outras habilidades.

Outros autores enfatizam a pedagogia crítica (PANIAGUA et al., 2018), onde há o reconhecimento do estudante como agente de modificação social. Trata-se da capacidade construída por um sujeito que se apropria de seus contextos sociais e realidades, são autônomos e capazes de criticar e argumentar com base em concepções teóricas e práticas para a criação e iniciativas que convergirão em alternativas para transformações sociais. A capacidade de argumentação dos alunos de engenharia foi investigada por Pereira e Hayashi (2019). Os autores propuseram uma atividade baseada no padrão de argumentos de Toulmin (TAP) e perceberam, além da fragilidade da argumentação, a dificuldade dos alunos em argumentar de maneira contrária às suas próprias convicções. Em uma proposta de atividade colaborativa mediada por mídia social e aplicada em três turmas com o total de participação de 127 alunos, Mello (2016) também destaca a fragilidade da capacidade de colaboração e cooperação dos alunos de engenharia civil.

Machado entende competência como uma característica pessoal que é exercida em um contexto específico a partir das relações que o ser humano estabelece com o meio (MACHADO, 2002). A competência pode ser associada à manifestação de saberes para atender demandas complexas sendo necessária a mobilização de recursos psicossociais, incluindo habilidades e atitudes, em um contexto específico (MACHADO, 2002).

Ao tomar como central a atividade de trabalho humano, a ergologia ${ }^{2}$ apresenta um conceito de competência mais abrangente, qual seja o de competência industriosa. A competência industriosa envolve não somente os conhecimentos acessados pelos sujeitos em um curso de formação, mas também os saberes investidos ${ }^{3}$ construídos nas dimensões históricas, no cotidiano de trabalho bem como os valores construídos por estes nas relações estabelecidas no trabalho (BRITO, 2008; SCHWARTZ, 1998). O ser industrioso não só mobiliza os saberes investidos (VERÍSSIMO, 2015) necessários para a realização das prescrições considerando que

\footnotetext{
${ }^{2}$ Abordagem pluridisciplinar de situações de trabalho, desenvolvida pelo filósofo Yves Schwartz desde 1993 na Universidade de Aix-Marseille Université- AMU, na França.

${ }^{3}$ Um saber investido no corpo-si das pessoas ao longo da vida que permite ao Homem responder às necessidades do meio. Trata-se de um saber que não está sistematizado em nenhum lugar, mas que se manifesta ao ser convocado no aqui e agora. Quando o saber investido for sistematizado ele é desinvestido e se torna um saber constituído.
} 
nem tudo pode ser prescrito, mas também atua transformando o meio em que se encontra inserido. (BRITO, 2008; SCHWARTZ, 1998).

De acordo com o National Research Council (2012), as competências estão relacionadas à capacidade de atender demandas complexas através da mobilização de recursos psicossociais, incluindo habilidades e atitudes, em um contexto específico. O comitê subdividiu em três os domínios de competência: cognitivo, intrapessoal e interpessoal, ver Quadro 1. Esses domínios representam distintamente o pensamento humano. O domínio cognitivo envolve razão, solução de problemas e memória, todos relacionados ao raciocínio. Intrapessoal é o domínio afetivo que se relaciona à emoção e aos sentimentos e inclui o autocontrole. Finalmente, o domínio das competências interpessoais que se referem a como o sujeito expressa informação para os outros e interpreta as mensagens recebidas de outras pessoas, verbal ou não verbalmente, e responde apropriadamente.

Quadro 1 - Domíos de competências para as Habilidades do Século XXI.

\begin{tabular}{|c|c|c|}
\hline \multicolumn{2}{|c|}{ Competências } & \multirow[t]{2}{*}{ Habilidades do Século XXI } \\
\hline Domínios & Grupos & \\
\hline \multirow{3}{*}{ Cognitivo } & $\begin{array}{l}\text { Processo } \\
\text { cognitivo e } \\
\text { estratégias }\end{array}$ & $\begin{array}{l}\text { Pensamento crítico, capacidade para solucionar } \\
\text { problemas, para fazer análises, para estabelecer razão e } \\
\text { argumentação, para interpretação, para tomar decisão e } \\
\text { para aprendizagem adaptativa }\end{array}$ \\
\hline & Conhecimento & $\begin{array}{l}\text { Domínio sobre busca de informações (pesquisas com } \\
\text { evidências e reconhecimento de viés em fontes), } \\
\text { domínio das tecnologias da informação e comunicação, } \\
\text { comunicação oral e escrita; escuta ativa }\end{array}$ \\
\hline & Criatividade & Criatividade e inovação \\
\hline \multirow{3}{*}{ Intrapessoal } & $\begin{array}{l}\text { Abertura } \\
\text { intelectual }\end{array}$ & $\begin{array}{l}\text { Flexibilidade, adaptabilidade, apreço à arte e cultura, } \\
\text { responsabilidade pessoal e social (incluindo } \\
\text { consciência cultural), apreço à diversidade, adaptação, } \\
\text { aprendizagem contínua, interesse e curiosidade }\end{array}$ \\
\hline & $\begin{array}{c}\text { Ética no } \\
\text { trabalho/ } \\
\text { Conscientização }\end{array}$ & $\begin{array}{l}\text { Iniciativa, autodirecionamento, responsabilidade, } \\
\text { perseverança, produtividade, bravura, autocontrole tipo } \\
1 \text { (habilidades metacognitivas, incluindo premeditação, } \\
\text { desempenho e autorreflexão), profissionalismo e ética, } \\
\text { integridade, } \\
\text { cidadania, orientação de carreira }\end{array}$ \\
\hline & $\begin{array}{l}\text { Autoavaliação } \\
\text { positiva }\end{array}$ & $\begin{array}{l}\text { Autocontrole tipo } 2 \quad 2 \quad \text { (automonitoramento, } \\
\text { autoavaliação, autorreforço), saúde física e mental }\end{array}$ \\
\hline \multirow[t]{2}{*}{ Interpessoal } & $\begin{array}{l}\text { Trabalho em } \\
\text { grupo e } \\
\text { colaboração }\end{array}$ & $\begin{array}{l}\text { Comunicação, colaboração, trabalho em grupo, } \\
\text { cooperação, coordenação, } \\
\text { empatia, } \\
\text { orientação, solução de conflitos, negociação }\end{array}$ \\
\hline & Liderança & $\begin{array}{l}\text { Liderança, responsabilidade, comunicação assertiva, } \\
\text { autoapresentação, influência social com os outros }\end{array}$ \\
\hline
\end{tabular}

Fonte: Adaptado de National Research Council (2012)

A Resolução CNE/CES 2/2019 (BRASIL, 2019) instituiu as Diretrizes Curriculares Nacionais do Curso de Graduação em Engenharia estabelecendo em seu artigo $3^{\circ}$ o perfil desejado para este profissional: 
I - ter visão holística e humanista, ser crítico, reflexivo, criativo, cooperativo e ético e com forte formação técnica; II - estar apto a pesquisar, desenvolver, adaptar e utilizar novas tecnologias, com atuação inovadora e empreendedora; III - ser capaz de reconhecer as necessidades dos usuários, formular, analisar e resolver, de forma criativa, os problemas de Engenharia; IV - adotar perspectivas multidisciplinares e transdisciplinares em sua prática; V considerar os aspectos globais, políticos, econômicos, sociais, ambientais, culturais e de segurança e saúde no trabalho; VI - atuar com isenção e comprometimento com a responsabilidade social e com o desenvolvimento sustentável.

Diante da evidente necessidade de se repensar o processo de ensino-aprendizagem nos cursos de engenharia no Brasil, foi realizada uma pesquisa - intitulada Compreender o trabalho para transformá-lo: a prática docente na sala de aula dos cursos de engenharia do IPUC, com financiamento do Fundo de Incentivo à Pesquisa-FIP. A pesquisa contemplou três dos cursos de engenharia do Instituto Politécnico da Pontifícia Universidade Católica de Minas Gerais (IPUC-Minas). O principal objetivo desta pesquisa foi compreender a prática docente exercida nestes cursos presenciais de engenharia da PUC Minas com a finalidade de transformá-la, se necessário. Foram utilizados três instrumentos para a coleta de dados: questionários para alunos e professores, observação de aulas de alguns professores que responderam aos questionários e, formação de um Grupo de Encontros do Trabalho (GET) ${ }^{4}$. Este artigo apresenta os resultados obtidos por meio do primeiro instrumento utilizado para a coleta de dados, o questionário. Nesta etapa os objetivos foram: (a) conhecer a prática docente a partir do olhar do aluno; (b) conhecer a prática docente a partir do olhar do próprio professor; (c) comparar as visões dos alunos e professores sobre a prática docente no IPUC; (d) refletir sobre as práticas comuns adotadas, considerando-se algumas das categorias das teorias pedagógicas ou abordagens de ensino que mais destacam nas práticas dos professores brasileiros, segundo Mizukami (1986). Em sua obra a autora analisa cada uma das linhas pedagógicas a partir das seguintes categorias: concepção de homem, de mundo, de sociedadecultura, de educação, de escola, e dos elementos do processo de ensino-aprendizagem tais como: objetivos, Conteúdo/conhecimento, Método-relação Professor-aluno e avaliação.

\section{METODOLOGIA}

Professores e alunos de três cursos do Instituto Politécnico da Pontifícia Universidade Católica de Minas Gerais (IPUC-Minas) foram convidados a responder um questionário sobre a prática pedagógica comumente adotada nestes cursos. As mesmas orientações passadas aos alunos foram apresentadas aos professores que aceitaram participar desta pesquisa. Cem pessoas responderam aos questionários, sendo que destas setenta e duas eram alunos $(29 \%$ Engenharia Civil, 20\% Engenharia de Energia, e 51\% da Engenharia Metalúrgica) e, vinte e oito eram professores (39,3\% Engenharia Civil, 42,8\% Engenharia de Energia, e 17,9\% Engenharia Metalúrgica).

Os alunos responderam a um questionário impresso que foi distribuído em sala de aula e recolhido no início da aula posterior. O questionário dos alunos foi dividido em três blocos de questões, a saber: informações pessoais para caracterização do grupo de alunos (5 questões de

\footnotetext{
${ }^{4}$ Trata-se de um dispositivo de pesquisa e intervenção em que pesquisadores e sujeitos da pesquisa, em posições de igualdade se reúnem, definem as diretrizes para o grupo, baseado em um problema no trabalho e buscam construir uma resposta para este problema. Este dispositivo foi desenvolvido pela Ergologia e seu mote é compreender o trabalho para transformá-lo.
} 
múltipla escolha), aula/prática pedagógica dos professores (11 questões de múltipla escolha em escala de Likert e uma questão discursiva) e autoavaliação (6 questões de múltipla escolha em escala de Likert).

Os professores responderam a um questionário online disponibilizado na plataforma Google Forms. O questionário dos professores foi dividido em dois blocos: informações pessoais para caracterização do grupo de respondentes (7 questões de múltipla escolha) e aula/prática pedagógica dos professores (11 questões de múltipla escolha em escala de Likert e uma questão discursiva). As questões relacionadas à aula/prática pedagógica são as mesmas em ambos os questionários, entretanto, houve alguma adaptação verbal, pronominal etc., para o questionário dos professores. Na questão discursiva foi solicitado que tanto alunos quanto professores expusessem, com relação à prática docente adotada atualmente, os aspectos positivos e os que poderiam ser melhorados.

Foi realizada uma análise qualitativa dos dados coletados para as repostas às questões de múltipla escolha em escala de Likert. As respostas da questão discursiva, tanto para os aspectos positivos quanto para os que precisariam ser melhorados na prática docente, foram categorizadas seguindo o mesmo critério utilizado por Mizukami (1986) ao analisar algumas das abordagens do processo de ensino-aprendizagem. Nesta pesquisa foram consideradas as seguintes categorias: concepção de homem, concepção de sociedade, conhecimento, relação professor-aluno, metodologia-técnica e avaliação.

\section{RESULTADOS}

Dos alunos respondentes a maioria pertence ao curso de Engenharia Metalúrgica (51,0\%), é do gênero masculino $(51,0 \%)$, está cursando o $10^{\circ}$ período $(51,4 \%)$, estuda no turno da noite $(75,0 \%)$ e está envolvida com alguma atividade profissional $(63,9 \%)$. Para os professores respondentes, a maioria pertence ao curso de Engenharia de Energia (42,8\%), o gênero preponderante entre todos é o masculino $(60,7 \%)$, a maioria tem idade superior a 50 anos $(53,6 \%)$ e $57,1 \%$ se dedica somente à docência. A maioria dos professores $(57,1 \%)$ possui experiência significativa no ensino superior ultrapassando os 15 anos de atuação. Dentre os professores participantes, $60,7 \%$ disseram ter cursado alguma disciplina relacionada à metodologia ou didática do ensino superior.

No Gráfico 1 tem-se a porcentagem das ocorrências de cada item da escala de Likert adotada para a pergunta 2.1 (Os recursos citados a seguir, para a apresentação ou discussão dos conteúdos das disciplinas, foram utilizados com qual frequência?), para ambos, professores e alunos. Tanto os professores $(78,6 \%)$ quanto os alunos $(84,7 \%)$ afirmaram que o recurso mais utilizado durante as aulas foi o quadro branco (lousa) e, em segundo lugar, a projeção de slides, para professores $(46,4 \%)$ e para alunos $(61,1 \%)$. Embora quase a totalidade dos professores afirmem que não utilizam o retroprojetor, praticamente a metade dos alunos respondentes $(55,6 \%)$ afirmaram que o retroprojetor ainda é bastante utilizado. A maioria de ambos, professores $(67,9 \%)$ e alunos $(77,8 \%)$, concordam que as redes sociais não são utilizadas como recursos didáticos.

No Gráfico 2 tem-se as respostas da questão 2.2 (Com qual frequência os professores usaram as técnicas de ensino a seguir?). As quatro técnicas mais utilizadas na prática docente, segundo as respostas dos professores, são: aula expositiva $(67,9 \%)$, resolução de exercícios $(46,4 \%)$, resolução de problemas baseados em situações reais $(42,9 \%)$ e trabalho em grupo $(32,1 \%)$. Na visão dos alunos, ver Gráfico 3, as técnicas mais utilizadas são: trabalho em grupo $(56,9 \%)$, apresentação de trabalhos $(55,6 \%)$, aula expositiva $(54,2 \%)$ e laboratório $(47,2 \%)$. 
(C) COBENCE

"Os desafios para formar hoje o engenheiro do amanhã"
$\mathrm{Ol} \mathrm{a} \mathrm{O3}$ de dezembro Evento On-line

Aqueles itens que não foram respondidos estão computados no grupo NR nos Gráficos 1, 2 e 3. O Quadro 2 apresenta a legenda para a técnicas mencionadas.

Quadro 2 - Legenda para as abreviaturas das técnicas apresentadasnos Gráficos 2 e 3.

\begin{tabular}{|c|l|c|l|}
\hline AE & Aulas expositivas & VE & Visitas externas \\
\hline RE & Resolução de exercícios & D & Debates \\
\hline TG & Trabalhos em grupos & EC & Estudos de caso \\
\hline AP & Apresentações de trabalhos & RP & Resolução de problemas \\
\hline O & Oficinas & EP & Elaboração de protótipos e produtos \\
\hline L & Laboratórios & & \\
\hline
\end{tabular}

Gráfico 1 - Recursos utilizados, segundo as respostas dos professores e alunos

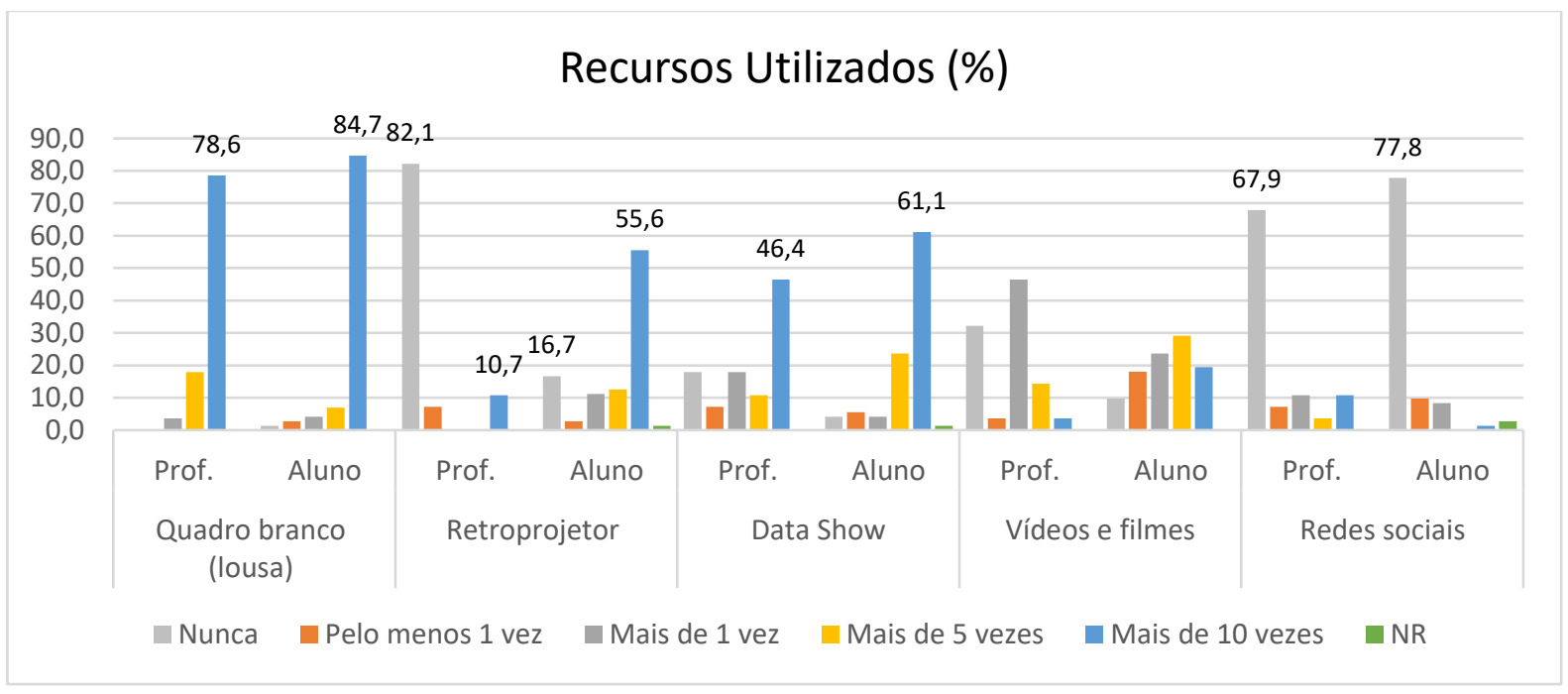

Fonte: elaborado pelas autoras.

Gráfico 2 - Técnicas utilizadas, segundo as respostas dos professores

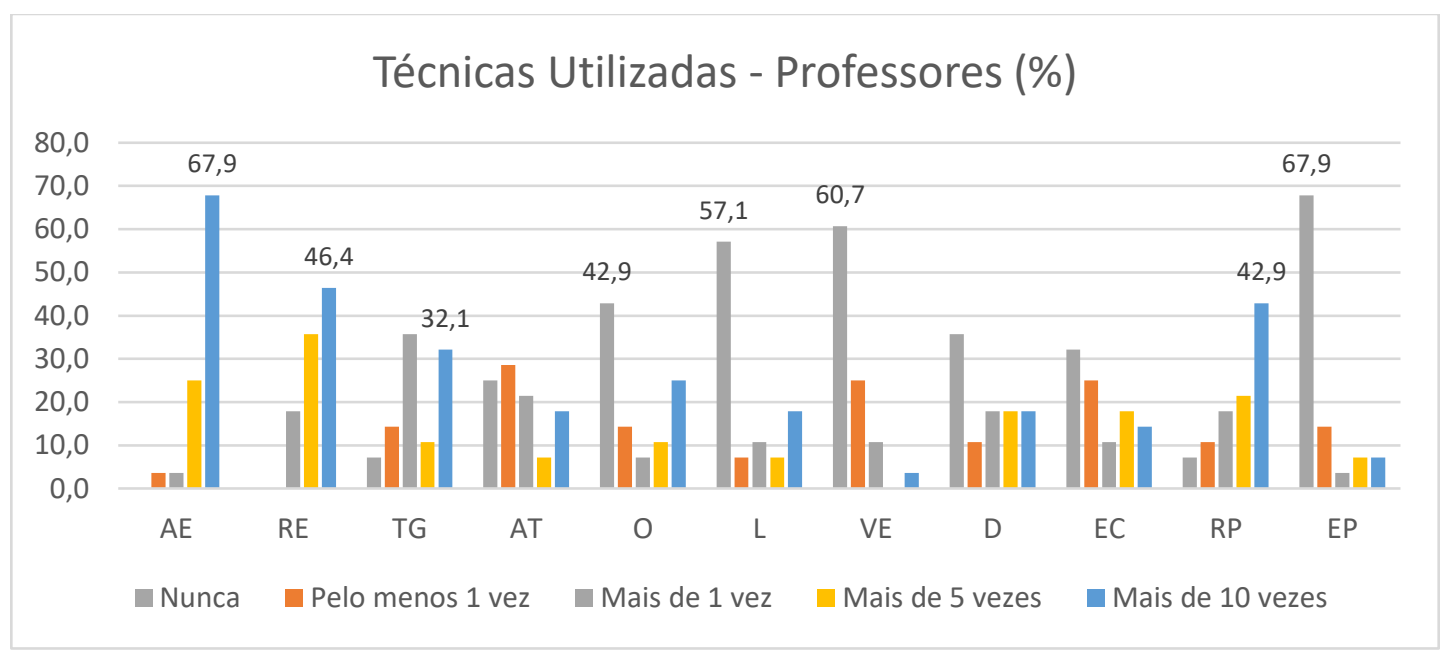

Fonte: elaborado pelas autoras. 
Gráfico 3 - Técnicas utilizadas segundo as respostas dos alunos

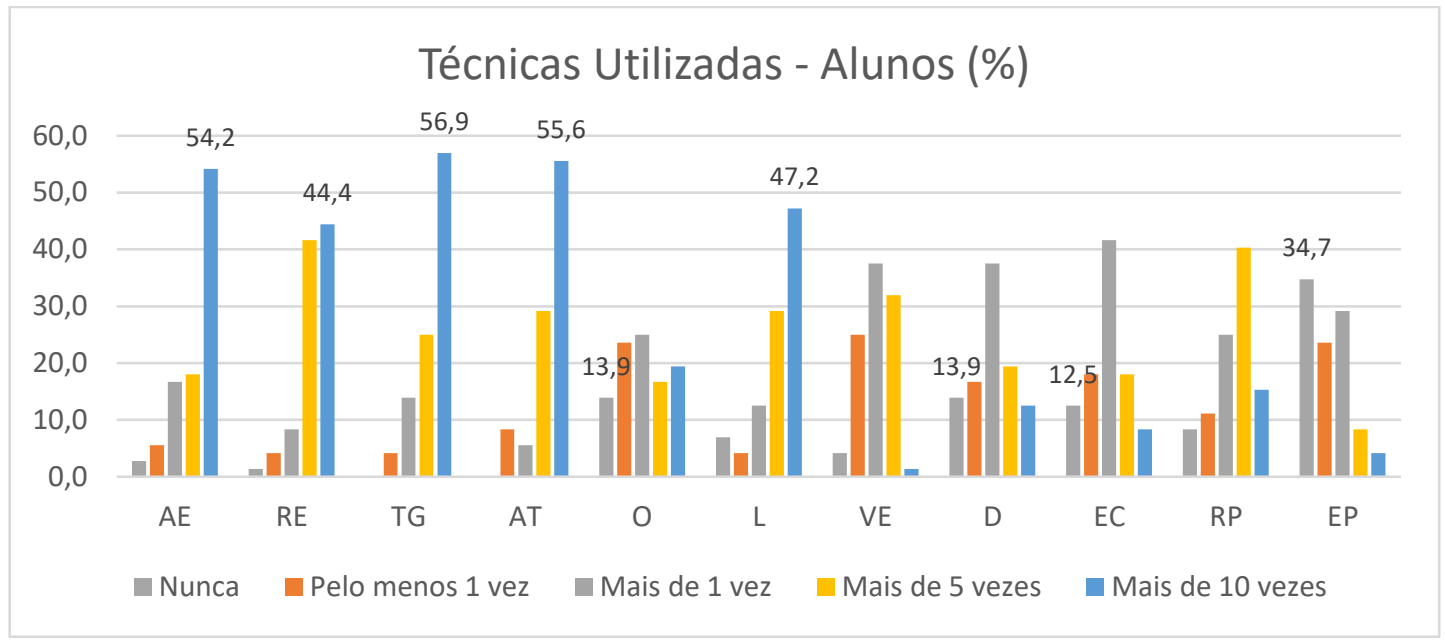

Fonte: elaborado pelas autoras.

Segundo os professores, as técnicas mais relatadas como nunca usadas são: elaboração de protótipos $(67,9 \%)$, visita externa (técnica) $(60,7 \%)$, laboratório $(57,1 \%)$ e oficina $(42,9 \%)$, ver Gráfico 2. Na visão dos alunos, ver Gráfico 3, as técnicas mais relatadas como nunca usadas são: elaboração de protótipos $(34,7 \%)$, debates $(13,9 \%)$, oficina $(13,9 \%)$ e estudo de caso $(12,5 \%)$.

No Gráfico 4 pode-se observar que para os professores os três principais aspectos positivos da prática docente nos cursos de engenharia do IPUC estão relacionados às seguintes categorias: metodologia/técnica $(61,3 \%)$, relação professor-aluno $(22,6 \%)$ e conhecimento $(9,7 \%)$. Para os alunos os principais aspectos positivos relatados também estão relacionados às mesmas categorias: metodologia/técnica $(42,0 \%)$, conhecimento $(24,0 \%)$ e relação professor-aluno $(16,0 \%)$.

Gráfico 4 - Relatos de professores e alunos para os aspectos positivos da prática docente

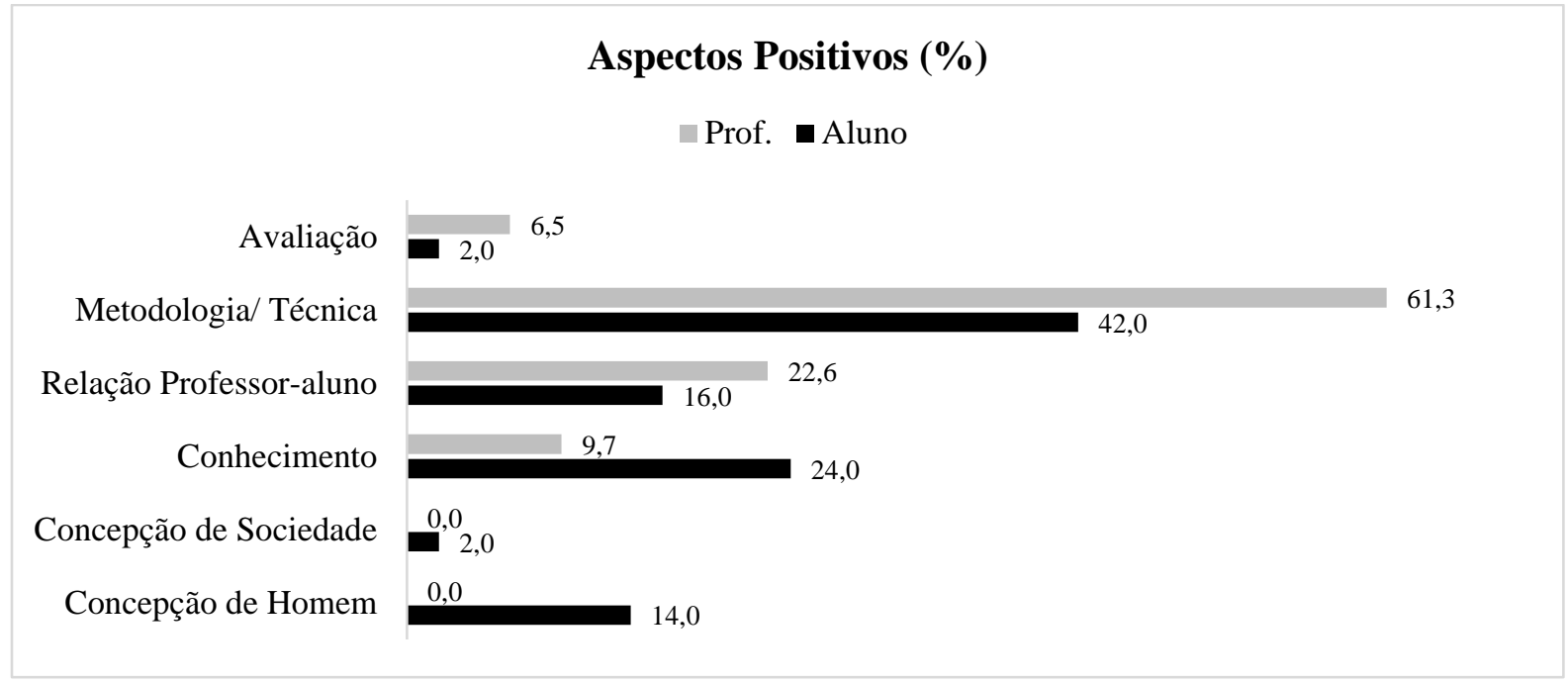

Fonte: elaborado pelas autoras.

Para os aspectos a serem melhorados, representados no Gráfico 5, os professores relataram como os três principais os relacionados às seguintes categorias: metodologia/técnica 
(74.3\%), avaliação $(11,4 \%)$ e relação professor-aluno $(5,7 \%)$. Do ponto de vista dos alunos o que precisa ser melhorado está relacionado a: metodologia/técnica $(65,6 \%)$, relação professoraluno $(17,2 \%)$ e conhecimento $(6,3 \%)$.

Gráfico 5 - Relatos de professores e alunos para os aspectos a serem melhorados na prática docente

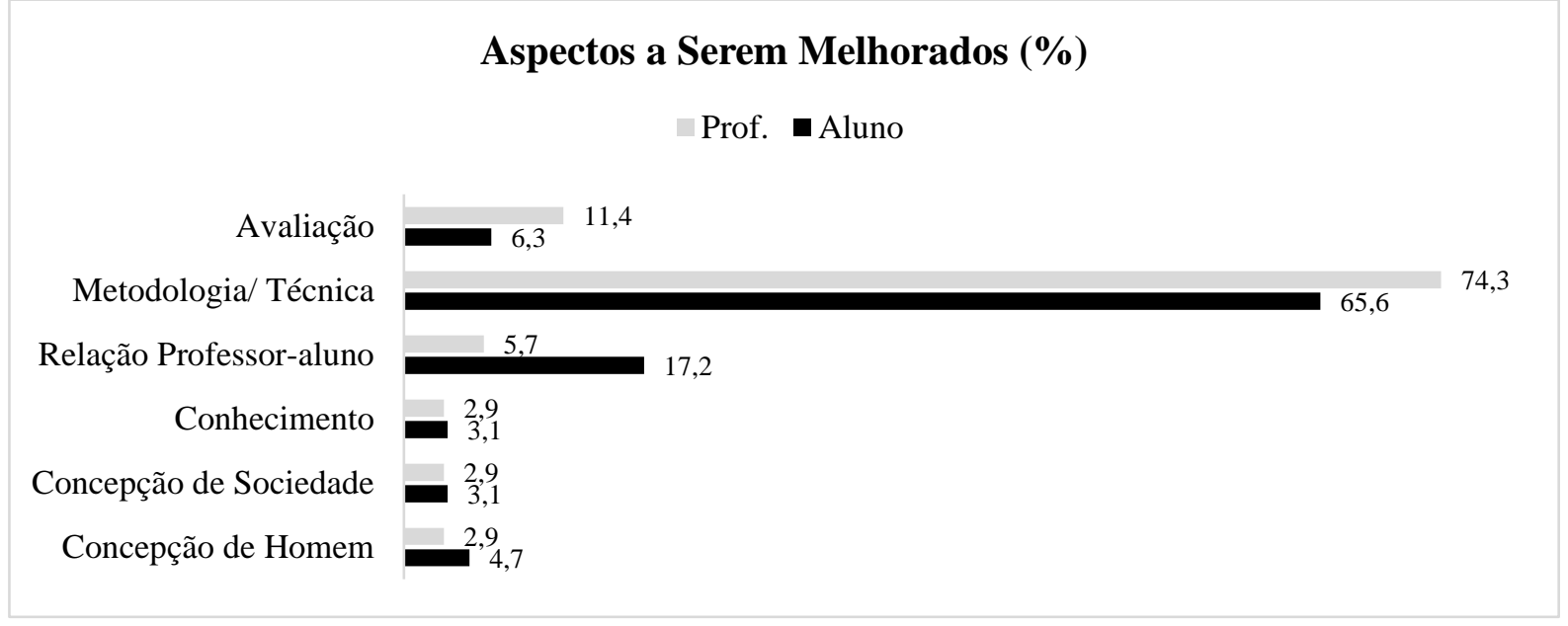

Fonte: elaborado pelas autoras.

\section{CONSIDERAÇÕES FINAIS}

A pesquisa revela que a prática pedagógica dos professores se baseia predominantemente em aulas expositivas com tendência à reprodução dos conteúdos por parte dos estudantes, por meio da resolução de exercícios. Há ênfase em situações de sala de aula e grande preocupação com o cumprimento da ementa e com o ensino dos conteúdos. Verifica-se que o principal objetivo do professor é a transmissão de um conteúdo previamente definido, pronto e acabado que figura nos livros e textos. Também há poucas ações que promovem a construção do conhecimento e a reflexão crítica por parte do aluno. Neste contexto o aluno é um sujeito passivo, com uma participação mínima nas aulas. Com essas características, confirma-se a hipótese de que a abordagem de ensino predominante nos cursos de Engenharia do IPUC é a tradicional (MIZUKAMI, 1986). Entretanto, a abordagem de ensino tradicional pouco contribui para o desenvolvimento das habilidades relacionadas aos três domínios de competências largamente recomendas para os engenheiros do século XXI: (1) cognitiva (pensamento crítico, capacidade de solucionar problemas, análise, argumentação, criatividade etc.); (2) intrapessoal (responsabilidade social, apreço à cultura e à diversidade, profissionalismo, ética, integridade, cidadania etc.); e (3) interpessoal (comunicação, colaboração, solução de conflitos, liderança etc.) (NATIONAL RESEARCH COUNCIL, 2012).

Quando se questiona, tanto aos professores quanto aos alunos, quais os aspectos positivos e quais podem ser melhorados na prática pedagógica dos professores, há um destaque para a metodologia/técnica adotada. Tamanha a sua importância, ela foi indicada como o principal aspecto positivo e, também, como o principal a ser melhorado neste contexto de processo de ensino e aprendizagem. Neste sentido, apenas com a avaliação do primeiro instrumento de coleta de dados, os questionários de professores e alunos, conclui-se que o processo de ensino e aprendizagem nos cursos de engenharia do IPUC pode ser aprimorado com a transformação da prática docente de seus professores. Inicialmente, considera-se como importante o cuidado dos professores ao planejar e executar as ações de ensino, para que estas ações propiciem uma participação mais ativa do aluno. Há necessidade de se repensar as metodologias e técnicas 
adotadas para que se possa promover a participação dos alunos em projetos engajados com as necessidades não só da sociedade como um todo, mas também do meio em que vivem e irão atuar. Assim, é importante que não só professores, mas toda a comunidade acadêmica seja envolvida no processo, promovendo oportunidades e incentivando a participação dos alunos em projetos e práticas extensionistas e projetos contextualizados e comprometidos com o desenvolvimento social.

\section{Agradecimentos}

As autoras agradecem aos coordenadores, professores e alunos do IPUC - PUC Minas dos cursos envolvidos nesta investigação pela participação ativa neste projeto e as bolsistas e colaboradores Paula Verdan Veríssimo, Brhenda Gonçalves Mendes, Camila Nogueira dos Santos Oliveira e Gabriel Philippe Martins Corrêa.

\section{REFERÊNCIAS}

BRASIL. 2019. Resolução CNE/CES 2/2019. Diretrizes Curriculares Nacionais do Curso de Graduação em Engenharia. Brasília: Ministério da Educação, 2019. Disponível em: http://portal.mec.gov.br/component/content/article?id=12991. Acesso em: 10 abr. 2020.

BRITO, Jose Eustáquio de. Restruturação da Telemar e a constituição de competência industriosa na operação de serviços aos usuários: uma investigação a partir da abordagem ergológica. 2008. Tese (Doutorado em Educação) - Faculdade de Educação, Universidade Federal de Minas Gerais, Belo Horizonte.

CRUZ, Cristiano Cordeiro. Engenheiro educador: experiências brasileiras de formação do perfil técnico capaz de praticar engenharia popular. Revista Iberoamericana de Ciencia, Tecnología y Sociedad, Buenos Aires, v. 14, n.40, 2019. Disponível em:

http://www.revistacts.net/volumen-14-numero-40/352-articulos/872-engenheiro-educadorexperiencias-brasileiras-de-formacao-do-perfil-tecnico-capaz-de-praticar-engenharia-popular. Acesso em: Acesso em: 20 jun. 2020.

KELLER-FRANCO, Elize; MASETTO, Marcos Tarciso. Currículo por Projetos: Repercussões Para a Inovação na Educação Superior e no Ensino de Engenharia. Revista Espaço do Currículo, João Pessoa, v. 11, n.1, p. 14-28, 2018. Doi: 10.22478/ufpb.1983$\underline{1579.2018 \mathrm{v} 1 \mathrm{n} 11.28548 \text {. }}$

MACHADO, Nilson José. Sobre a ideia de competência. In: PERRENOUD, Philippe (Org.). As Competências para ensinar no Século XXI. Porto Alegre: Artmed Editora, 2002. p. 137-155.

MASETTO, Marcos Tarciso. Competência Pedagógica do Professor Universitário. $2^{\text {a }}$ ed. São Paulo, SP: SUMMUS, 2012.

MELLO, Gláucia Nolasco de Almeida. Wikis no Ensino Superior: Uma Atividade em Equipe para Mensurar o Potencial Colaborativo dos Alunos. Revista Tecnologias na Educação, v. 17, 2016. Disponível em: http://tecedu.pro.br/ano8-numerovol17/. Acesso em: 30 jun. 2020.

MIZUKAMI, Maria da Graça Nicoletti. Ensino: As Abordagens do Processo. São Paulo, SP: EPU, 1986. 
NATIONAL RESEARCH COUNCIL (org.). Education for Life and Work: Developing Transferable Knowledge and Skills in the 21st Century. Committee on Defining Deeper Learning and 21st Century Skills, J.W. Pellegrino and M.L. Hilton, Editors. Washington, DC: The National Academies Press. 2012.

PANIAGUA, Piedad María Metaute; OSORIO, Giovanny Alberto Flórez; CONTRERAS, Paul Andrés Rúgeles; CASTAÑO, Diego Alberto. La dinamización de las estrategias pedagógicas actuales: una necesidad aplicable a los procesos de enseñanza y aprendizaje de los estudiantes de ingeniería del siglo XXI. Revista Lasallista de Investigación, Antioquia, v. 15, n. 1, p. 46-56, 2018. Doi: 10.22507/rli.v15n1a4.

PEREIRA, Vágner Ricardo de Araújo; HAYASHI, Carlos Roberto Massao. Controvérsias Sociotécnicas: Uma Proposta Didática para o Ensino de Engenharia. Revista IberoAmericana de Estudos em Educação, Araraquara, v. 14, n. 2, p. 526-542, 2019. Doi: 10.21723/riaee.v14i2.11374.

SCHWARTZ, Yves. Os ingredientes da competência: Um exercício necessário para uma questão insolúvel. Educ. Soc., Campinas, v. 19, n. 65, p. 101-140, 1998. Doi: 10.1590/S010173301998000400004.

VERÍSSIMO, Mariana. Elementos para construção da noção de saber investido. Trabalho \& Educação, Belo Horizonte, v.24, n.2, p. 295-313, 2015.

\title{
UNDERSTANDING THE TEACHING PRACTICE OF PUC MINAS ENGINEERING TEACHERS: POINT OF VIEW OF STUDENTS AND TEACHERS
}

\begin{abstract}
This article is part of research funded by the FIP PUC Minas program whose main objective was to understand the teaching practice in the engineering courses at PUC Minas to transform it, if necessary. The instrument used for data collection that was the basis for the discussions in this text was the printed questionnaire answered by the students and the online questionnaire answered by the teachers. All students of the Civil Engineering, Energy Engineering and Metallurgical Engineering courses, enrolled in the 8th, 9th and 10th periods and, all teachers of the same courses, were invited to participate in the research. A total of one hundred people agreed to participate in this stage of the research-seventy-two students and twenty-eight teachers. For both teachers and students, the main positive points in the pedagogical practice of teachers were methodologies and techniques adopted, knowledge of teachers and teacher-student relationship. The students pointed out that the main points to be improved are the methodologies and techniques adopted, and the teacher-student relationship. The teachers considered as aspects to be improved, the methodologies and techniques adopted as well as the evaluation strategies. This investigation highlights the importance of the methodologies and techniques adopted for the pedagogical practice and, at the same time, highlights the need for its transformation so that it can contribute effectively developing the necessary competences of future engineers.
\end{abstract}

Keywords: Engineering education. Teaching practices. Competences' development. 